\title{
Esgotamento do mundo atual: as condições materiais da reflexão sobre mundos possíveis na filosofia continental contemporânea
}

\author{
The exhaustion of the present world: \\ the material conditions for the thinking \\ of the possible worlds problem in \\ contemporary continental philosophy
}

\section{Rafael Saldanha}

Doutor em filosofia pela UFRJ, professor substituto no departamento de filosofia da UFRJ

Resumo: No presente texto, buscamos discutir as condições materiais que explicam o surgimento de certas investigações sobre mundos possíveis na filosofia continental contemporânea. Nossa hipótese é que essa questão surge no contexto de uma crise da imaginação e da crise climática, ambas resultantes dos movimentos internos à própria modernidade. Realizamos uma análise da gênese da modernidade e da sua crise a partir das obras de Reinhart Koselleck e Paulo Arantes, mostrando como há uma relação intrínseca entre o surgimento da modernidade como um movimento orientado para um horizonte de expectativas e, posteriormente, um movimento de decrescimento desse horizonte de expectativas. Nesse contexto, nos parece ser possível identificar o que une as discussões sobre mundos possíveis na filosofia continental contemporânea: trata-se de um movimento de tentativa 
de superação do esgotamento do mundo atual a partir de um movimento intensivo de pluralização dos mundos possíveis interiores ao mundo atual.

Palavras-chave: Mundos possíveis; Esgotamento; Reinhart Koselleck; Paulo Arantes

Abstract: In the present article, we intend to discuss the material conditions that explain the arisal of a certain number of discussions on 'possible worlds' in contemporary continental philosophy. Our hypothesis is that this question arises from the context of a crisis of imagination and the climate change crisis that result from the inner movements of modernity. Thus, we perform an analysis of the genesis of modernity and its crisis from the works of Reinhart Koselleck and Paulo Arantes, showing the intrinsic link between the beginning of modernity, as a movement oriented towards a horizon of expectations and, afterwards, as a movement of decrease in this same horizon of expectations. It is from this context that it seems possible to identify what unites certain discussions on 'possible worlds' in those philosophies: it seems to be a movement that tries to overcome the exhaustion of the current world through an intensive movement that pluralizes the possible worlds inside the actual world.

Keywords: Possible worlds; Exhaustion; Reinhart Koselleck; Paulo Arantes

\section{Introdução}

$\mathbf{O}$

presente trabalho tem como objetivo analisar a especificidade do reavivamento do problema dos mundos possíveis em um determinado ramo da filosofia continental contemporânea. Queremos mostrar que a questão não somente é retomada por alguns autores, como transformada de acordo certas exigências do presente. Nosso interesse, portanto, não se restringe ao âmbito da história da filosofia; isto é, não queremos apenas utilizar a questão dos mundos possíveis para compreender esse grupo particular de filósofos. Investigaremos, antes, as características específicas dessa retomada, que, como argumentaremos, nos parece ter surgido como resposta a uma crise da temporalidade que tem como consequência a experiência de esgotamento do presente. Graças a esse diagnóstico, torna-se visível todo um novo campo de investigação filosófico, 
justamente aquele que tem sido explorado pelos filósofos em questão. A ideia de mundos possíveis abre um caminho para explorar as dobras internas do real, ou seja, os mundos possíveis imanentes ao nosso próprio mundo, que podem nos fornecer alternativas para repensar as crises que temos enfrentado.

A possibilidade de identificar as características da filosofia em uma determinada era, ou mesmo apenas um certo movimento filosófico específico, depende da nossa capacidade de circunscrever um grupo de filósofos relevantes em um mesmo conjunto. Circunscrição essa que pode ser feita atentando ao compartilhamento de certos princípios, de escolhas metodológicas ou mesmo de questões que se apresentam como problemas a serem pensados em um determinado momento. Se isso já foi mais fácil em algum momento da história ou se trata-se apenas de uma ilusão retrospectiva, não nos interessa muito. O que nos importa é que, no presente, a quantidade imensa de trabalhos realizados em todos os cantos do mundo fazem parecer quase impossível a possibilidade de síntese. Ainda assim, acreditamos que talvez seja possível encontrar questões e temas que nos possibilitem compreender ao menos grupos de autores específicos, sem uma pretensão de dar conta do espírito do tempo em sua totalidade. Com isso em mente, mais do que uma concordância de princípios ou métodos compartilhados, apostamos aqui que um problema filosófico pode servir como ponto de apoio para iluminar alguns dos trabalhos mais interessantes da filosofia continental contemporânea ${ }^{8}$.

$8 \quad$ Usamos a expressão filosofia continental com toda a cautela que ela merece. Apesar dessa distinção continental/analítica ser problemática (sobretudo por apontar para uma divisão assimétrica entre uma "filosofia analítica" e uma "filosofia não-analítica"), ainda assim pode nos servir como orientação para melhor localizar o trabalho recente dos autores mencionados. Pensamos, portanto em autores como Isabelle Stengers (Stengers, 2015), Quentin Meillassoux (Meillassoux, 2012 e Meillassoux, 2015), Déborah Danowski e Eduardo Viveiros de Castro (Danowski; Viveiros de Castro, 2014, mas também VIVEIROS DE CASTRO, 2015), Steven Shaviro (Shaviro, 2016), Markus Gabriel (Gabriel, 2015), Pierre Montebello (Montebello, 2015) e Bruno Latour (Latour, 2012). Não se trata de uma lista exaustiva, apenas de um número de autores que vem retomando esse problema e que tem, nesse processo, dialogado direta ou indiretamente, como se podem inferir das referências que esses autores fazem entre si. 
Para fins de delimitação provisória, chamaremos os autores que nos interessam de novos realistas ${ }^{9}$. Certamente não refletem o pensamento "continental" como um todo, mas a retomada de certos temas por esses autores, ainda que nem sempre referidos explicitamente ao seu solo tradicional, talvez nos permita dar-lhes alguma unidade. É por isso que nos voltamos para o problema dos mundos possíveis. Acreditamos que, se há uma unidade nesse conjunto, é por conta, em parte, de uma retomada diferente do problema dos mundos possíveis. Sabe-se que esse problema tem como principais expoentes Leibniz e David Lewis. É a partir da obra desses autores que ele geralmente é pensado. No caso dos autores a que nos referimos, porém, esse problema costuma aparecer mediado pela leitura que Gilles Deleuze faz da

$9 \quad$ A questão de como reunir esse grupo de pensadores que me refiro é, em si, objeto de disputa. Trata-se de um grupo de autores (uma lista desses autores podem ser encontrados na coletânea The Speculative turn (Bryant; Srnicek; Harman, 2011), que serve ao menos de gatilho para a reunião de certos autores "aparentemente" divergentes) que começam a dialogar diretamente ou compartilhar referências em comum a partir de meados dos anos 2000, mas que nem sempre se harmonizam em princípios filosóficos semelhantes. Mas, como muitas vezes essas diferenças são conflitantes, nem sempre é fácil construir uma denominação que acolha esse grupo de autores. Essas dificuldades explicam a variedade de nomes que têm sido sugeridos nos últimos tempos para dar conta desses autores: realistas especulativos (cf. Niemoczynski, 2017), novos materialistas (Coole; Frost, 2010) e novos realismos (Ferraris, 2014) são apenas alguns dos nomes que têm sido discutidos. Mas se muitas vezes há conflito nos princípios adotados por esses autores, que interesse haveria em reuni-los sob uma rubrica? Acredito que isso se dá por conta de uma certa convergência de problemas. Ainda que os autores acabem construindo filosofias que muitas vezes se opõem diretamente aos princípios de outras desse mesmo grupo, a impressão que se passa é que ainda assim o mesmo território está sendo disputado. Isso nos parece especialmente fértil se levarmos em conta que uma certa produtividade da filosofia, uma certa riqueza, está justamente nesse diálogo de diferentes. Daí persistirmos, ainda que nem sempre com sucesso, tentando compreender conjuntamente um grupo de autores que, como dissemos, nem sempre se harmonizam. Se optamos pela expressão "novos realistas" é por ser uma expressão que realiza um baixo nível de comprometimentos teóricos,, considerando as diferentes formas que um realismo pode assumir (ainda que ciente de que a vagueza desses termos é em si um problema que deve ser resolvido eventualmente). No entanto, isso não é o objeto desse artigo, de modo que deixaremos essa discussão para um outro momento. 
obra de Leibniz ${ }^{10}$, o que explica a torção específica que encontramos nesses textos. Nosso objetivo aqui não é, portanto, simplesmente se perguntar outra vez sobre a questão dos mundos possíveis na filosofia continental contemporânea. O que faremos é recolocá-la a partir de novos problemas. Vemos no livro $O$ que é a filosofia?, de Deleuze e Guatarri, uma descrição dessa questão que torna claro o que estará em jogo para esses autores: o problema dos mundos possíveis aparecerá, aqui, na forma da noção de outrem, visto que essa noção "não aparece aqui como um sujeito, nem como um objeto, mas, o que é muito diferente, como um mundo possível, como a possibilidade de um mundo assustador. Outrem é, antes de mais nada, a existência de um mundo possível." (Deleuze; Guattari, 1997, p. 28). A associação entre a questão dos mundos possíveis e uma certa alteridade implicará em novas coordenadas ${ }^{11}$ para o problema, visto que "este mundo possível tem também uma realidade própria em si mesmo, enquanto possível: basta que aquele que exprime fale e diga 'tenho medo', para dar uma realidade ao possível enquanto tal". (Deleuze; Guattari, 1997, p. 28).

Nessa leitura deleuzo-guattariana do problema, a noção de mundos possíveis articulada à questão da alteridade aparece, portanto, como um campo imanente ao real ainda a ser explorado. É esse ponto de partida que nos ajuda a entender melhor o fato de haver uma unidade possível dos autores referidos acima. O que está em jogo, como diz Tristan Garcia em uma das poucas descrições precisas desse movimento recente dos novos realistas (que ele denominará “ontologia liberal contemporânea), é

a investigação por princípio de uma indiferença fundamental entre entidades subjetivas e objetivas, que são entidades diferentes, mas que não são diferentemente. O sentido de libera-

10 Seja uma herança direta do problema (caso de autores como Isabelle Stengers, Steven Shaviro, Déborah Danowski, Eduardo de Viveiros de Castro (para ficar em alguns), seja indiretamente, como nos casos de Markus Gabriel, Graham Harman (entre outros), que chegam nesses problemas a partir do diálogo com os primeiros.

11 "Este conceito de outrem remete a Leibniz, aos mundos possíveis de Leibniz e à mônada como expressão de um mundo; mas não é o mesmo problema, porque os possíveis de Leibniz não existem no mundo real." (Deleuze; Guattari, 1997, p. 29) 
lidade na ontologia consiste, portanto, a igualar os objetos e as figuras de subjetividade, mente, alma, ego transcendental, consciência intencional, sujeito humano, sujeito não humano, que se encontram consideradas como objetos comuns como os outros. (Garcia, 2018, p. 53)

O que Garcia realça como elemento comum dos novos realistas é justamente a ideia da filosofia como um movimento de exploração dos mundos possíveis que compõem a realidade. A partir de uma premissa de um certo campo comum de indiferença ontológica ${ }^{12}$, a tarefa da filosofia seria justamente explorar os inúmeros mundos possíveis diferentes que povoam esse plano imanente. É o que vemos nas obras de autores como Bruno Latour (Latour, 2012) e Markus Gabriel (Gabriel, 2015), em suas investigação dos diversos modos de existência. Também na maneira como Isabelle Stengers (Stengers, 2010) examina as implicações políticas das ciências naturais em sua cosmopolítica. Ou então no trabalho de Steven Shaviro (Shaviro, 2016) de compreender os diferentes mundos esboçados pela ficção científica. E, por fim, também nas análises de Déborah Danowski e Eduardo Viveiros de Castro (Danowski; Viveiros de Castro, 2014) sobre os tipos de "fim do mundo" que existem no nosso. Acreditamos que, em alguma medida, esses autores ${ }^{13}$ podem ser identificados a partir desse mesmo problema, que impõe esse mesmo movimento identificado por Garcia:

O objetivo não é anular a subjetividade, mas produzir ontologias realistas em sua liberalidade, afim de reconstruir o que se considera como um ou os sujeitos, de modo que a indiferenciação realista entre objetividade e subjetividade é de fato a condição necessária para a reforma das subjetividades que não seriam mais pressupostas ou aceitas tacitamente, seguindo as regras da nossa língua, da nossa cultura, do nosso tempo. Esperamos antes dispôr sob um mesmo plano de realidade subjetividade e objetividade, de modo a melhor realizar a possibilidade de outras formas de subjetividade. (Garcia, 2018, pp. 53-54)

\footnotetext{
12 Se quisermos marcar a herança deleuziana, poderíamos falar de um "plano de imanência" ou de uma "univocidade" de fundo como condição do real. 13 Como já mencionamos em outro momento, não cabe aqui fazer um exame exaustivo desse movimento por falta de espaço. Nossa intenção é apenas apresentar as linhas gerais de uma unidade.
} 
Mas não é apenas isso que gostaríamos de fazer aqui; isto é, identificar historicamente as referências que podem ter influenciado tal grupo. O que desejamos é entender como esse problema tem também uma fonte material. Isto é, como esse reavivamento do problema dos mundos possíveis não seria por acaso, mas estaria lastreado em certas crises pelas quais passamos, notadamente a experiência atual de esgotamento político, econômico e ecológico.

Não nos parece surpreendente que a questão dos mundos possíveis se coloque novamente no momento em que nos deparamos com uma das maiores crises que a humanidade já enfrentou. De maneira resumida, podemos apontar dois elementos dessa crise: o primeiro pode ser descrito como uma espécie de crise da imaginação, um esgotamento, tal como descrito por Mark Fisher em seu livro Capitalismo realista (Fisher, 2009), produzido pelas sucessivas crises do capitalismo democrático (cf. Streeck, 2016). Nesse contexto, como diz a famosa piada relembrada por Fredric Jameson, torna-se mais fácil imaginar o fim do mundo do que o fim do capitalismo. Haveria, portanto, uma dificuldade em pensar alternativas políticas mesmo com crises sucessivas na dinâmica do capital global. Para nosso azar, o segundo elemento é a crise ecológica (Danowski; Viveiros de Castro, 2014, pp. 19-29). Se é difícil imaginar uma alternativa política para o momento presente, a dificuldade de imaginar um futuro para a nossa espécie torna a questão ainda mais complicada. Estamos diante de uma crise que envolve um duplo esgotamento do futuro: material e imaginário.

Nossa hipótese é, portanto, que esse contexto torna ainda mais relevante as discussões sobre o problema dos mundos possíveis. Isso se torna ainda mais claro quando lembramos que a questão é posta classicamente no campo metafísico, como dão mostras seus principais expoentes, G. W. Leibniz e David Lewis. Gostaríamos, portanto, de percorrer um outro caminho para entender como esse problema aparece de outra forma nos autores que agrupamos como 'novos realistas'. Mesmo existindo inúmeras divergências entre eles, essa linha de investigação nos parece proveitosa, pois uma coisa que podemos afirmar sobre todos é que, de uma forma ou de outra, a questão dos 
mundos possíveis se relaciona com uma espécie de esgotamento do mundo atual. A investigação dos mundos possíveis acaba sendo uma ferramenta de exploração intensiva a partir do momento em que a esfera extensiva (isto é, o mundo material) se encontra comprometida (Latour, 2017, p. 291). A questão dos mundos possíveis surge, portanto, como uma forma de tentar superar essa condição de esgotamento, ainda que isso se desenvolva das formas mais variadas possíveis, desde a experimentação dos "fins do mundo" possíveis por Danowski e Viveiros de Castro (Danowski; Viveiros de Castro, 2014) à investigação sobre os "mundos cognitivos diversos" que Shaviro encontra em livros de ficção científica (Shaviro, 2016).

Pretendemos, pois, investigar como essa questão surge a partir de um certo desenvolvimento histórico e material. Para tal, nos apoiaremos nos trabalhos de Reinhart Koselleck e Paulo Arantes, dois autores que buscam entender a dinâmica da modernidade a partir da sua temporalidade. Suas análises são relevantes porque deixam bem clara a maneira como a temporalidade da modernidade é orientada por um mundo possível, a saber, um horizonte que não é da ordem da experiência, mas da expectativa (Koselleck, 2006, p. 312). Faremos, então, uma reconstrução das análises de Koselleck e Arantes para tornar claras as condições materiais que explicam a reflexão sobre o problema dos mundos possíveis na filosofia continental contemporânea. Certamente não temos como objetivo esgotar completamente a questão, mas acreditamos que é possível iluminar o elemento filosófico desse problema ao pôr em destaque o contexto a partir do qual as suas discussões emergem. Por meio dessa análise, acreditamos que as demandas implícitas dessa reformulação do problema e as especificidades das suas soluções se tornam mais claras, permitindo um engajamento mais pleno com seus aspectos propriamente conceituais.

\section{A temporalidade moderna}

Segundo Koselleck, é possível entender a modernidade por meio de um jogo entre o par de conceitos espaço de experiência e horizonte de expectativas. Recorrendo a esse par, seria 
possível observar as mudanças na estrutura temporal que constituem uma época e que a diferenciam de uma época precedente. Isso seria possível, segundo Koselleck, porque o uso dessas categorias permitiria compreender o entrelaçamento entre passado e futuro, de modo que o que chamamos de modernidade seria apenas uma configuração específica do tempo concebida através desse par (Koselleck, 2006, p. 308).

Koselleck traça as transformações da nossa experiência do tempo por meio do jogo de variações que essas categorias vão sofrendo. Como diz o autor, "o tempo histórico não apenas é uma palavra sem conteúdo, mas também uma grandeza que se modifica com a história, e cuja modificação pode ser deduzida da coordenação variável entre experiência e história." (Koselleck, 2006, p. 309) Com esses conceitos em mãos, torna-se possível demarcar uma série de momentos distintos (ainda que a sua periodização possa ser problematizada) que delineiam diferentes regimes temporais.

Precisamos, portanto, entender esse par de conceitos antes de entrar na análise propriamente dita da natureza temporal da modernidade. Com relação ao espaço de experiência, o conceito não está muito distante do que seu nome sugere. Trata-se da reserva de acontecimentos que mobilizamos na hora de agir. Não é um mero passado, mas o passado presente atualmente (Koselleck, 2006, p. 309). No entanto, é justamente por ser um acúmulo que acaba condensando uma série de acontecimentos provenientes de momentos diferentes. Como, porém, o tempo não para de passar, à medida que as coisas acontecem, essa aglomeração tende a se transformar e a se reorganizar. Por exemplo, fatos recentes podem implicar em uma retificação do passado, sem que ele seja de todo negado.

Se a experiência é a forma que o passado adquire no presente, a expectativa, por outro lado, é a forma que o futuro assume na atualidade. Ela é a nossa orientação para aquilo que ainda não se concretizou, é uma experiência possível daquilo que não pode ser experimentado, por mais estranho que isso pareça. Como dirá o autor, ela "também pode ser objeto de experiência. Mas nem as situações, nem os encadeamentos de 
ações visadas pela expectativa podem também ser desde já objeto da experiência.” (Koselleck, 2006, p. 312) E é por conta disso que se, por um lado, falamos de espaço de experiência, por outro falaremos de horizonte de expectativa, visto que este termo diz respeito justamente a um aspecto da realidade que não pode ser experimentado diretamente.

Essa diferença aponta para a topologia específica de cada um desses conceitos, implicando uma ausência de simetria entre eles. Para Koselleck, as estruturas são radicalmente diferentes, já que "uma experiência, uma vez feita, está completa na medida em que suas causas são passadas, ao passo que a experiência futura, antecipada como expectativa, se decompõe em uma infinidade de movimentos temporais." (Koselleck, 2006, p. 310) Mesmo que não seja possível simplesmente deduzir o futuro a partir do passado, o tipo de relação que eles estabelecem acaba, como já dissemos, resultando em uma forma específica do tempo, em épocas determinadas com dinâmicas temporais singulares. Esses conceitos nos permitem visualizar a maneira como a ideia de tempo se articula e se altera na história do ocidente. Além disso, é importante lembrar que as categorias têm uma relação que é mais da ordem de uma retroação dialógica do que uma simples causalidade linear. É claro que o horizonte de expectativas é parcialmente condicionado e delimitado pelo espaço de experiência. Como condição, o espaço de experiência provoca um certo recorte na ordem do possível, delimitando um horizonte indefinido, mas não infinito. Segundo Koselleck, "o que antecede é o diagnóstico no qual estão contidos os dados da experiência. Visto dessa maneira, o que estende o horizonte de expectativa é o espaço de experiência aberto para o futuro. As experiências liberam os prognósticos e os orientam." (Koselleck, 2006, p. 313) É justamente porque a expectativa se caracteriza por ser a presença de um horizonte do não experimentado que esse horizonte não tem como ser completamente delimitado pela experiência. Em alguma medida, ele tem que ir justamente para além desse espaço, e a maneira como esse horizonte de expectativa é manejado, a partir do prognóstico, pode inclusive reorganizar o próprio espaço de experiência ao privilegiar certas regiões da experiência em detrimento de outras. A plasticidade 
dessa relação é, portanto, sua principal característica. "Não se pode conceber uma relação estática entre espaço de experiência e horizonte de expectativa. Eles constituem uma diferença temporal no hoje, na medida em que entrelaçam passado e futuro de maneira desigual." (Koselleck, 2006, p. 313)

A alteração dos regimes temporais, para Koselleck, é justamente o jogo entre essas duas categorias. Vemos, na sua obra, a maneira como essas dinâmicas temporais conceitos foram se transformando e, consequentemente, alterando a experiência histórica para que ela assumisse a forma que tem hoje — que não é, como vimos, simplesmente um desenrolar a partir do passado, mas também uma orientação em direção ao não experimentado. Seguindo os fios percorridos por Koselleck, conseguimos entender como chegamos às crises que vivemos atualmente graças a um desenvolvimento imanente à própria história.

Conforme descrito por Koselleck, a modernidade emerge ela própria de uma outra estrutura temporal. O autor data o nascimento desse novo período na Revolução Francesa, ainda que esse novo tempo histórico tenha sido fruto de um longo período de gestação que pode ser remontado à formação dos estados absolutos e às grandes navegações (Koselleck, 1999, pp. 19-47). Como podemos descrever essa alteração na estrutura temporal? Segundo Koselleck, se o tempo europeu pré-moderno (desde os romanos, ao menos) era de ordem escatológica (Koselleck, 2006, pp. 24-26), a partir da Revolução Francesa, o tempo como um progresso linear vai paulatinamente se tornando a experiência temporal predominante (Koselleck, 2006, p. 37). Koselleck dirá, então, que

na era moderna a diferença entre experiência e expectativa aumenta progressivamente, ou melhor, só se pode conceber a modernidade como um tempo novo a partir do momento em que as expectativas passam a distanciar-se cada vez mais das experiências feitas até então. (Koselleck, 2006, p. 314)

No entanto, essa transformação, como dissemos, não é imediata: ela é gestada e é composta por duas quebras. A primeira quebra se dá no momento (amplo) da instauração dos 
estados absolutistas, a partir da paz de Westfália e da chegada dos europeus em terras americanas. No momento anterior a essa primeira quebra - o velho tempo da Europa - , ao menos desde o momento em que a religião cristã dominava a Europa, o tempo era regido por uma expectativa do apocalipse. Temos, nesse caso, um tempo em que a própria instituição cristã se constrói e estabiliza sob essa ameaça escatológica. Nessa temporalidade, as expectativas para além da experiência ficavam em um espaço fora desse mundo: "As expectativas que se projetavam para além de toda experiência vivida não se referiam a este mundo. Estavam voltadas para o assim chamado além, apocalipticamente concentradas no fim do mundo como um todo." (Koselleck, 2006, pp. 315-316) As profecias de transformação radical, na medida em que fracassavam, garantiam a repetibilidade terrena. O que esse fracasso mostrava era tanto uma perenidade do espaço da experiência como uma indestrutibilidade do horizonte de expectativa. Essa temporalidade persistia porque nenhuma das promessas de transformar a estrutura do presente se confirmava, reiterando o caráter repetitivo do tempo presente e organizando a vida terrena a partir dessa possibilidade de se construir ações apoiadas na confiabilidade do passado. Quanto ao futuro, como ele era constitutivamente fora de toda experiência vivida, nada que acontecesse no mundo teria qualquer efeito nele, "tratava-se, pois, de expectativas que não podiam ser desfeitas por nenhuma experiência contrária, porque se estendiam para além deste mundo." (Koselleck, 2006, p. 316) Conseguimos ver que aqui o espaço de experiência é que acaba tendo prevalência sobre o horizonte de expectativa. Isso não quer dizer que "nada mudava", mas que o ritmo das mudanças era tão lento que poderíamos dizer que ele sempre tinha tempo para ser recebido e acomodado (Koselleck, 2006, p. 317).

A primeira ruptura que acontece graças aos eventos mencionados é justamente com respeito a esse caráter escatológico. A partir do fortalecimento da "forma" Estado, vemos as profecias do fim dos tempos serem trocadas pelo desenvolvimento da arte dos prognósticos. Nesse período de transição, também é possível observar que, com a separação (nos reporta- 
mos ao indispensável Crítica e crise) entre as esferas política e religiosa (ou moral), o novo estado soberano, em sua tentativa de perpetuar seu corpo, acaba por desenvolver uma técnica de prospectar o futuro para antecipar problemas e lidar com eles. (Koselleck, 2006, pp. 32-33)

Não se trata mais de ter uma articulação de uma temporalidade delimitada por um fim-dos-tempos certo, mas indeterminável, como horizonte. Há uma transformação que começa a ocorrer: é a própria técnica de prever-e-se-organizar que acaba por dar ordem às coisas. É com isso em mente que Koselleck dirá que "o objetivo de uma perfeição possível, que antes só podia ser alcançado no além, foi posto a serviço de um melhoramento da existência terrena, que permitiu que a doutrina dos últimos fins fosse ultrapassada, assumindo-se o risco de um futuro aberto." (Koselleck, 2006, p. 316) O horizonte deixa de ser paciente e se torna agente na organização da temporalidade moderna. ${ }^{14}$

A segunda ruptura, gestada entre a paz-de-Westfália/chegada-nas-Américas e a revolução francesa, é o momento em que o par de conceitos trabalhados acima (a saber, espaço de experiência e horizonte de expectativa) tem a sua relação alterada de maneira decisiva. Na primeira ruptura, quebra-se com o aspecto escatológico da história: fica-se sem o fim dos tempos, mas a relação com o futuro é tal que a orientação para a ação ainda subordina o horizonte de expectativa ao espaço da experiência. O jogo que se joga é de caráter cíclico (algo fundamental na arte de fazer prognósticos) e, só com o germinar de uma nova técnica de lida com o futuro (a saber, a filosofia da história) e a maneira como ela, em parte, precipita a revolução francesa (Koselleck, 1999, pp. 111-161), é que podemos dizer que o tempo da modernidade se instaurou. Essa transformação pode ser descrita em dois níveis. Primeiramente há o fato de que nesse momento os fluxos do capital passam a percorrer todo o globo, integrando-o pela primeira vez na história — fato que será comentado mais adiante.

$14 \quad$ Ainda que não pretendamos percorrer esse caminho, há uma linha de investigação possível que se abre aqui. Trata-se da investigação da relação entre essas transformações descritas por Koselleck, que se dão ao longo dos séculos XVI e XVIII e a reflexão sobre os mundos possíveis de Leibniz, permitindo, possivelmente, contextualizar as condições históricas da sua filosofia. 
Há ainda uma outra transformação que se relaciona ao par de conceitos que estamos trabalhando: é apenas nesse instante que o futuro vai aparecendo como algo que não é mais da ordem do prognóstico ou da previsibilidade; ele se apresenta como algo de ordem desconhecida, não experimentável. O horizonte de expectativa vai se distanciando do espaço de experiência e a prática da política se insere justamente nessa tentativa de agir sem muitos amparos.

A novidade era a seguinte: as expectativas para o futuro se desvincularam de tudo quanto as antigas experiências haviam sido capazes de oferecer. E as experiências novas, acrescentadas desde a colonização ultramarina e o desenvolvimento da ciência e da técnica já não eram suficientes para servir de base a novas expectativas para o futuro. A partir de então o espaço de experiência deixou de estar limitado pelo horizonte de expectativa. Os limites de um e de outro se separaram." (Koselleck, 2006, p. 318)

É preciso, então, reavaliar o funcionamento da experiência e da expectativa nesse novo quadro. Segundo Koselleck, a mudança fundamental é que, à medida em que concebemos a história como um progresso contínuo, "o horizonte de expectativa passa a incluir um coeficiente de mudança e se desenvolve com o tempo." (Koselleck, 2006, p. 318) O horizonte não é mais absolutamente atrelado (indexado) à experiência que se tem, então ele próprio acaba funcionando como uma força que impulsiona o presente para além daquilo que já foi experimentado. A transformação no conceito de experiência, por sua vez, ocorre na medida em que diversos acontecimentos que apontam para momentos e tendências diferentes de desenvolvimento começam a participar do mesmo tempo. Nas palavras de Koselleck, "todas essas experiências remetiam à contemporaneidade do não contemporâneo, ou inversamente, ao não contemporâneo no contemporâneo." (Koselleck, 2006, p. 317). Nessa transformação, que é a composição de uma história global, pode-se falar cada vez menos de experiências que não estão conectadas entre si. A história começa a ser vista como uma totalidade única, mas aberta em direção a um futuro. Mas este também é único, ainda que diferente de seu passado, visto que se encontra concebido a partir do signo de um progresso. (Koselleck, 2006, p. 319) 
Essa dupla transformação que ocorreu nos conceitos fez com que eles tivessem a sua articulação alterada. Na modernidade, o horizonte de expectativa, por ter um coeficiente de mudança interno, passa a não ser mais determinado pelo espaço de experiência. Isso se torna tão senso comum que pensadores contemporâneos a essa transformação "afirmar[mam] que nenhuma experiência anterior pode servir de objeção contra a natureza diferente do futuro torna-se quase uma lei." (Koselleck, 2006, p. 318) O choque provocado pela Revolução Francesa foi tão grande, tão intenso e tão rápido que, em poucos anos, destruiu-se a relação anterior entre expectativa e experiência, em que a primeira era delimitada pela segunda. Isso não quer dizer que o espaço de experiência se torna nulo, mas podemos dizer que, se antes a expectativa estava contida na experiência, agora esta apenas condiciona aquela.

Se era possível afirmar que a relação anterior era relativamente estável, pois o tempo era da ordem da repetição por ser estruturado a partir do passado e do que já era da ordem do conhecimento, o que encontramos na nova temporalidade moderna é uma instabilidade que decorre da orientação rumo ao futuro, isto é, ao não experimentado. Koselleck caracterizará essa instabilidade a partir da dinâmica do progresso, na medida em que "quanto menor o conteúdo de experiência, tanto maior a expectativa que se extrai dele. Quanto menor a experiência tanto maior a expectativa - eis uma fórmula para a estrutura temporal da modernidade, conceitualizada pelo 'progresso'." (Koselleck, 2006, p. 326) Dito isso, o que veremos abaixo é que, na verdade, é essa movimentação rumo ao futuro que acaba nos conduzindo para o esgotamento que experimentamos atualmente.

Há, porém, um aspecto fundamental desse processo que é deixado de lado por Koselleck e que talvez o impeça de antecipar o movimento de transformação imanente ao próprio regime temporal que ele buscou descrever detalhadamente. Trata-se do papel do lento movimento de hegemonização das relações capitalistas na constituição desse tempo da modernidade. Uma das razões para se destacar esse elemento é que 
a situação de esgotamento que vivemos atualmente nasce do confronto entre a dinâmica interna do Capital — isto é, seu movimento de valorização (Marx, 2013, p. 228) - e a política absolutista. Só podemos compreender o movimento imanente desse tempo moderno quando conseguimos relacioná-la com a intensificação dos processos de produção e acumulação. Não nos interessa entrar em detalhes exaustivos sobre a constituição da era capitalista. O que importa deixar claro é que em determinado momento emerge uma dinâmica autônoma da acumulação como um fim em si mesmo, "dispensando a muleta de algum conjunto de valores e regras básicos que fosse aceito ativamente pela classe esclarecida e, ao menos passivamente, pelo povo comum." (Arantes, 2014, p. 49)

Dessa sede insaciável por acumulação, surge a necessidade de se expandir para além das fronteiras europeias. A descoberta de novas rotas comerciais graças às cruzadas e a intensificação e o fortalecimento das grandes cidades comerciais do mediterrâneo acabam provocando as grandes expedições ultramar que culminaram nas ocupações europeias da América. Esse movimento, que parece ser o simples crescimento das vias de circulação de riquezas pelo mundo, é na realidade o ponto de partida para a constituição do tempo moderno — isto é, o primeiro momento em que uma sincronicidade global se torna possível —, ou seja, o tempo em que a história começa a se tornar uma totalidade única por meio da constituição de uma "economia-mundo europeia em expansão na forma de ciclos sistêmicos de acumulação" (Arantes, 2014, p. 49). É com isso em mente que Arantes desloca - contra o provincianismo koselleckiano - o processo de instauração da temporalidade moderna para o encontro entre Europa e América. Segundo o autor, considerando

a centralidade da expansão colonial para a consolidação da economia-mundo capitalista, será plausível afirmar que, sem o combustível daquela acumulação atlântica de experiências realizadas em uma Fronteira histórica inédita, não se constituiria no continente europeu um novo ou, por outra, propriamente dito horizonte de expectativa, sem a abertura do qual - se os esquemas de Koselleck estão corretos - não se poderia falar de um Neuzeit. (Arantes, 2014, p. 44) 
O movimento de acumulação de capital não é apenas complementado pela colonização. É a própria expansão das fronteiras (a saber, os locais de progressiva acumulação de capital) que permite que um capitalismo histórico se consolide. Com base nas análises de Immanuel Wallerstein sobre o capitalismo histórico, destacamos dois elementos que indicam a necessidade dessa expansão. Primeiramente, não a globalização é mais que a capacidade de capturar novos mercados; o que ocorre é mais uma globalização da divisão de trabalho. (Wallerstein, 2001, pp. 36-37). Se o movimento do Capital é sobretudo uma extração de mais-valor, então faz sentido que a sua expansão geográfica exporte para as suas fronteiras a dominação pelo trabalho.

O segundo aspecto que induz a essa necessidade é a maneira como "novas incorporações ao sistema capitalista tenderam a ocorrer em fases de estagnação da economia-mundo", de maneira que "torna-se claro que a expansão geográfica do sistema serviu para contrabalancear a queda nos lucros (provocada pelo aumento da proletarização), através da incorporação de novas forças de trabalho destinadas a ser semiproletarizadas." (Wallerstein, 2001, p. 37) Dessa forma, na medida em que as fronteiras vão se expandindo, surge um tempo global, que vai tomando forma como "uma economia-mundo capitalista, em expansão permanente desde o nascedouro, [que] só se legitima perante uma combinação paradoxal entre o sempre igual da acumulação como fim em si mesmo e um horizonte igualmente ilimitado de expectativas." (Arantes, 2014, p. 48) Mas talvez não seja possível ainda falar de um tempo plenamente moderno, visto que a sincronicidade - a coordenação entre os processos de produção em escala global que caracteriza, segundo Koselleck, a temporalidade moderna - ainda não se deu completamente. Mesmo assim, essa estrutura, com sua dinâmica interna de acumulação, é o suficiente para levar ao desenvolvimento do capitalismo industrial — que, agora sim, exerce uma pressão forte o suficiente para produzir a sincronicidade característica do novo tempo do mundo, na medida em que a produção capitalista passa a ser efetuada em escala global. 
Podemos dizer, então, agora com uma leitura mais encorpada pelas análises de Arantes, que durante esse processo de desenvolvimento do capitalismo é formado um tempo histórico próprio da modernidade, com uma orientação para o futuro. Trata-se da dinâmica, já exposta por Koselleck, em que o horizonte de expectativa vai se distanciando cada vez mais do espaço da experiência, a ponto de criar um futuro que não é mais delimitado pela experiência; o que nasce aqui é o "futuro aberto" que Koselleck descreveu. Não é de se estranhar que haja uma ressonância entre esse futuro aberto e o clássico diagnóstico de Marx e Engels no Manifesto Comunista sobre como as relações de produção capitalista dissolvem uma série de relações sociais que pareciam fixas e imutáveis (o espaço da experiência). (Marx; Engels, 2010, p. 43) Também em Marx (e Engels) é possível encarar a modernidade como a abertura de um horizonte.

E o momento que vivemos? Podemos dizer que se trata não de um novo tempo histórico, mas, como dissemos, do esgotamento da própria temporalidade moderna. Como diz Arantes, a situação atual pode ser descrita como uma espécie de "sociedade do risco que acarretaria precisamente uma tremenda reversão de todos os horizontes modernos de expectativa." (Arantes, 2014, p. 55). Passamos, portanto, por um momento em que o horizonte de expectativas passa a recuar em vez de se expandir. Como explicar essa transformação?

Para Arantes, o ponto de inflexão desse novo tempo começa com a experiência traumática da Primeira Guerra Mundial. $\mathrm{Na}$ fase da guerra de trincheiras, percebe-se em que as batalhas se encontraram travadas: os combatentes tendiam a perder a capacidade de agência, entrando, consequentemente, numa expectativa agonizante. A guerra só saiu desse estado de imobilidade geral quando foram desenvolvidas tecnologias que, por conta da sua alta potência bélica, acabariam por assombrar o horizonte de expectativa. É graças a esse novo fantasma técnico que a sensação de perda da capacidade de agir não se restringiu à Primeira Guerra Mundial, mas acabou contaminando a própria maneira como o horizonte de expectativas era vivido (Arantes, 
2014, p. 88). Não à toa, o período entreguerras foi de uma espera inquietante: espera da inevitável catástrofe que se anunciava no horizonte. A Segunda Guerra Mundial não demorou a vir, e com ela trouxe horrores piores ainda. Se no entreguerras o medo da catástrofe ainda podia ser encarado como um mero prenúncio mais ou menos indefinido, a industrialização do genocídio do povo judeu e a invenção da bomba atômica (e o seu uso no Japão) tornaram real o perigo de auto-aniquilação de toda a humanidade. Temos, portanto, uma inversão na direção do movimento do horizonte de expectativas que caracteriza a temporalidade moderna. Ao invés de expandir, ele passa a se retrair, ainda que permaneça como eixo de orientação.

O que vem depois desse horror, porém, a princípio não faz muito sentido. Após 1945, seguiu-se um período de trinta anos estranhíssimos. Ao mesmo tempo em que vivia-se sob a ameaça constante da catástrofe (da bomba, da Guerra Fria), esse perigo conviveu com uma aparente sensação de bem-estar privado, recolhendo em parte os benefícios, ao menos no atlântico norte, das políticas econômicas de bem estar social que existiam na Europa e na América do norte (Arantes, 2014, pp. 84-85).

Arantes argumenta, porém, que essa expectativa positiva era fundamental para o prosseguimento da vida. Esse duplo horizonte - uma camada de ilusão que prometia um futuro próspero de distribuição de riquezas - sustentaria uma mobilização total da população, mobilização esta que, de maneira invisível, já seria o próprio decrescimento das expectativas característico do esgotamento atual - trata-se, em suma, da gestação da sensação de cancelamento do futuro que vivemos plenamente hoje em dia. Parece estranho dizer que há essa duplicação; um momento de expectativas positivas (o welfare state) em meio a essa expectativa do fim (o apocalipse atômico). Talvez seja possível, porém, conceber esse momento como uma sobreposição entre a tendência expansiva da temporalidade moderna com a sua eventual retração, na medida em que uma germina enquanto a outra padece.

Desse modo, é a incapacidade de lidar com o trauma que impede de ver que aquela promessa de um futuro, na prática, já 
tinha sido destruída a ponto de os eventos traumáticos que ocorreram entre 1914 e 1945 serem reduzidos a um simples bump in the road, depois dos quais insistia-se que nada havia mudado. Não é à toa que é possível conceber a Guerra Fria como "um tremendo reservatório de sentidos" (Arantes, 2014, p. 90). Ela era uma engrenagem que ainda sustentava um horizonte de expectativa porque mantinha vivas as utopias de direita (os EUA, sobretudo, caminhando para uma plena distribuição de riqueza a partir do desenvolvimento de um "capitalismo consciente") e de esquerda (a promessa na URSS de uma sociedade em que os trabalhadores finalmente chegariam ao poder).

O que se escondia debaixo dessa camada ilusória de progresso era a realidade de que o espaço da experiência tinha sido completamente dissolvido e desmoralizado com os traumas relacionados à Primeira Guerra Mundial. Com isso em mente, pode-se olhar com outros olhos os tempos da Guerra Fria. O welfare state se torna apenas a face visível de um warfare state. Quando, porém, as crises econômicas e políticas começam a irromper a partir dos anos 70, a camada de ilusão (e a reserva de sentido que a garantia) rapidamente se desfaz e o movimento de retração das expectativas sobe à superfície. Por conta das ameaças que se intensificam e trazem à superfície o decrescimento que operava subterraneamente, o regime de um futuro aberto, que procurava ativamente o não experimentado, foi substituído por uma política de gestão de riscos. Os perigos cresceram a tal ponto (ao temor da bomba atômica se juntam as novas forças emergindo no campo geopolítico - China, os grupos extremistas islâmicos -, mas também a ameaça trazida pelas mudanças climáticas) que agora o próprio presente passa a correr riscos. Em nome de uma autopreservação, o primeiro a ser cancelado acaba sendo o futuro. O que isso quer dizer é que, na medida em que se torna cada vez mais difícil caminhar em direção a um determinado futuro (concretizá-lo), o horizonte de expectativas se torna um horizonte de riscos. Não procuramos mais pensar como alcançar uma certa expectativa;preocupamo-nos, agora, com os inúmeros fatores que põem em risco essa expectativa. Se antes a ação era positiva (construir um futuro), agora se torna negativa (evitar que o futuro 
desapareça). O problema é que, quando o tempo é encarado a partir de uma ideia de risco, isso faz com que a nossa vida se transforme em um gerenciamento de risco no presente. Os riscos passam a reduzir as possibilidades de futuro, fazendo com que ele volte a se aproximar do solo da experiência. O futuro enquanto horizonte do não experimentado, que organizava a articulação temporal da modernidade, passa a ser subordinado a um gerenciamento do presente que, devido ao risco, passa a conceber o futuro apenas como um presente preservado. Com o objetivo de garantir um mínimo de futuro, este se converte em um presente replicado (Arantes, 2014, p. 91), ou seja, na impossibilidade de progredir, busca-se apenas repetir indefinidamente o estado de coisas atuais. Eis, então, a situação atual: um esgotamento do futuro que nos impede de imaginar uma saída que não seja a simples repetição do mesmo.

É preciso deixar claro que esse tempo do risco já estava em germe desde as primeiras navegações, que inauguraram a aventura capitalista. É por isso que insistimos na centralidade (deixada de lado por Koselleck) das dinâmicas do Capital na constituição da temporalidade moderna. Ainda que a modernidade seja a libertação do horizonte de expectativas do espaço da experiência, num contexto em que se busca intensificar a acumulação de capital, essa relação com o futuro já se encontra em certa medida contaminada, pois há sempre a possibilidade de que o capital acumulado se destrua nessa empreitada (Arantes, 2014, p. 69). Enquanto os riscos forem baixos comparados aos ganhos, o movimento de acumulação pode continuar realizando suas apostas. Na medida em que essa relação começa a se inverter (os riscos aumentando, os ganhos potenciais diminuindo), o custo para as apostas cresce, por isso Paulo Arantes afirma que o futuro passa a ser visto como "um território a ser conquistado e colonizado'. Riscado do mapa, em suma, sob o pretexto de ser existencialmente assumido como um risco." (Arantes, 2014, p. 69)

O novo regime temporal que começa a se impor é uma colonização do tempo em nome da segurança do presente. $\mathrm{O}$ 
movimento de aceleração do horizonte de expectativa, que nos direcionava para a possibilidade de um não experimentado, acaba nos transformando em uma sociedade que não consegue sequer tolerar o risco. No entanto, o risco que se quer evitar não é qualquer um. O que se procura preservar é o movimento de acumulação de capital. É por isso que Arantes poderá dizer que "o Capital está agora consumindo o futuro" (Arantes, 2014, p. 73).

O que isso significa? Bem, significa, segundo Paulo Arantes, que, em nome do risco, a ideia de uma sociedade democrática vai lentamente sendo apagada, pois vão sendo impostos mecanismos de controle da população cada vez mais severos e abrangentes. Também significa que a dinâmica de acumulação de Capital vai se intensificando a tal ponto que não se pode nem mais controlá-la. Um retrato da evolução e das transformações dos tipos de intervenção na economia nas últimas décadas nos mostram claramente como os períodos entre as crises têm (após um breve hiato entre a Segunda Guerra Mundial e os anos 70) diminuído e as intervenções têm se mostrado cada vez mais ineficazes. Como diz Wolfgang Streeck, em sua análise da crise atual do capitalismo, "soluções se tornam problemas que exigem novas soluções que, porém, após mais ou menos outra década, se tornam elas mesmas problemas, exigindo outra solução que logo mostrou ter tão vida curta e ser tão autodestrutiva como suas predecessoras." (Streeck, 2016, p. 16) Essa dificuldade que se apresenta para o movimento de acumulação de Capital faz com que a convivência (analisada por Streeck) entre democracia e capitalismo se torne cada vez mais incompatível, gerando uma crise na imaginação, descrita por Fisher em Realismo capitalista, e que muitas vezes nos força a aceitar qualquer situação política com medo de perder ainda mais.

Se entendermos a democracia como uma das encarnações do horizonte de expectativas que se inaugura com a revolução francesa, fica ainda mais fácil entender a relação entre capital e horizonte de expectativas. A dificuldade progressiva de se acumular capital (um efeito da própria dinâmica interna do Capital já previsto por Marx) faz com que a relação com qual- 
quer horizonte de expectativas - nas inúmeras utopias de uma sociedade pós-escassez e de igualdade social — apareça, retrospectivamente, como um casamento com prazo de validade.

Esse casamento funcionou durante muito tempo por conta do medo das classes que realizavam essa acumulação. É isso que Arantes coloca em destaque quando, retomando Wallerstein, comenta as lições que foram extraídas da Revolução Francesa pela burguesia ascendente. A primeira delas é que, na Revolução, houve um risco de desestruturação dos mecanismos de hegemonia social. Uma coisa era a disputa (interminável) entre diversos grupos que buscavam controlar o poder e os instrumentos de dominação social, outra era a ameaça que as classes mais desfavorecidas ofereciam ao realizar "revoltas verdadeiramente antissistêmicas do mundo moderno, portadoras de uma ameaça real às polarizações estruturais do sistema-mundo capitalista." (Arantes, 2014, p. 92) O perigo que há nessa desestruturação leva à segunda lição aprendida: diante do medo de que se ameace a estrutura de acumulação de capital, produziu-se uma "tecnologia de gestão dos riscos de descarrilamento do sistema por excesso de expectativas, mediante uma astuciosa normalização da mudança social." (Arantes, 2014, p. 92) O "coeficiente de mudança" presente no horizonte de expectativa, como se vê, não é uma transformação tão inocente no regime temporal - tratou-se, durante muito tempo, de uma forma de apaziguamento dos ânimos. Segundo Arantes, a manutenção de um horizonte de expectativas pela realização de reformas planejadas acaba funcionando como uma promessa feita para estabilizar os ânimos presentes nas classes que são exploradas pela dinâmica social de exploração capitalista. A mudança, sempre calibrada e nunca excessiva, é normalizada como uma tecnologia que oferece uma mobilidade sem que as estruturas de poder sejam efetivamente transformadas. Trata-se do adágio enunciado pelo príncipe de Falconeri em O Leopardo: "tudo deve mudar para que tudo fique como está".

Essa tecnologia de gestão que fabricou o horizonte de expectativas começa a ruir a partir do século XX. No mesmo momento em que vemos o retorno da ameaça fantasmática da 
destruição do sistema, as expectativas encolhem e a perspectiva de uma utopia democrática some do horizonte (junto com o horizonte, visto que ela estaria intimamente associada a ele). As revoluções deveriam acelerar o tempo, abreviar aquilo que inevitavelmente aconteceria. O que ocorre, porém, com o seu fracasso repetido, somado à incapacidade de projetar uma situação distinta do presente, é que a única transformação possível a se desenhar no horizonte é a nossa própria extinção — seja por um lento definhamento no capitalismo, seja por uma acelerada aproximação do cataclisma ecológico. Não se trata de dizer que não haverá algo depois desses "fins do mundo". O que estamos dizendo é que, como o futuro nos aparece como uma mera repetição, qualquer mudança real parece tão impossível que, para que cheguemos lá, nós não poderemos mais ser os mesmos.

Em suma, os riscos não param de crescer e, com isso, o futuro vai sendo cancelado por meio de seu povoamento pelo presente. Isso é a causa do momento em que vivemos agora: um mundo incapaz de conceber uma realidade diferente da atual e que é condenado a uma gestão de riscos.

\section{Os mundos possíveis como saída para dentro.}

Podemos, agora, ver com mais clareza em que medida a crise que vivemos atualmente tem uma relação com a própria constituição da modernidade. O processo de acumulação capitalista é ao mesmo tempo aquilo que instaura o movimento direcional progressivo na história e aquilo que retira a própria possibilidade de progresso, quando atingido um certo limiar (que foi identificado no período que compreende as duas guerras mundiais na primeira metade do século XX). Além disso, cabe pontuar que essa acumulação é também causa do desequilíbrio climático que ameaça a própria existência material de um futuro. Nos encontramos, portanto, numa situação de completo esgotamento. Não é fácil enxergar possibilidades, seja no que diz respeito ao horizonte político ou nas questões climáticas.

Como, então, entender a retomada da questão dos mundos possíveis? Bem, como falamos, esses trabalhos mencionados anteriormente não procuram discutir as implicações pura- 
mente lógicas ou metafísicas da teoria dos mundos possíveis. Não se trata de afirmar ou negar alguma versão do realismo modal. O que está em jogo nesses textos é outra coisa: trata-se, antes, de um sintoma que pode ser explicado pela ausência de expectativas. Desse modo, o que encontramos é uma espécie de transporte do problema dos mundos possíveis para o interior do mundo atual, que se encontra, a princípio, esgotado.

Diante da incapacidade de imaginar alguma alternativa para este mundo, é como se os filósofos tivessem tomado como ponto de partida a necessidade de pluralizar o ponto de vista atual por meio de uma multiplicação dos mundos possíveis em uma ordem intensiva ${ }^{15}$. Estamos aqui contrapondo essa forma de pensar os mundos possíveis à maneira leibniziana; a saber, pensá-los como possibilidades além do mundo existente atual, isto é, que não existem fora do regime da possibilidade. O que encontramos no trabalho desses autores é justamente o contrário; é a investigação sobre os possíveis que existem de modo imanente ao nosso mundo atual. Esses autores agem como se apenas a superfície do mundo estivesse esgotada, havendo ainda um campo para minar e explorar que ainda não foi tocado pelo esgotamento. De modo que encontramos no grupo desses novos realistas uma tentativa de tentar superar o esgotamento do próprio mundo atual em que existimos.

Um caso emblemático desse movimento é o trabalho de um autor que já mencionamos, Steven Shaviro, que analisa como existem outros tantos mundos, para além da consciência humana, que podem emergir por meio da variação das condições cognitivas, ou seja, pela simples existência de outrem (Shaviro, 2016). Nesse sentido, o que essa imersão nas perspectivas pode fornecer é uma espécie de testemunho ou catálogo daqueles inúmeros mundos que se perdem no movimento de esgotamento que consome nosso tempo atual. Como diz Vinciane Despret (outra filósofa que poderia ser adicionada ao grupo discutido aqui): "Com cada extinção, algo da realidade do mundo desaparece." (Despret, 2014, p. 3). Também podemos enxergar esse mesmo movimento de pluralização intensiva

$15 \quad$ Uma sugestão que tiramos do trabalho de Raquel Azevedo (cf. Azevedo, 2019, p. 15). 
dos mundos possíveis no trabalho de Viveiros de Castro, em Metafísicas canibais, na medida em que ele desenvolve os conceitos de perspectivismo e multinaturalismo. A partir do ponto de vista ameríndio tal como descrito pelo autor, vemos uma pulverização da natureza que varia conforme variam os corpos que ocupam a uma determinada perspectiva ${ }^{16}$. Não se trata de dizer que uma mesma natureza se altera conforme muda a perspectiva, mas que a própria natureza varia dependendo do corpo que ocupa tal perspectiva, produzindo a insólita experiência em que "as coisas que eles veem, quando veem como nós vemos, são outras: o que para nós é sangue, para os jaguares é cerveja; o que para as almas dos mortos é um cadáver podre, para nós é mandioca fermentado (...), e assim por diante" (Viveiros de Castro, 2015, p. 64). De novo, nos vemos aí junto a uma reflexão que explicitamente parte de um processo de esgotamento da realidade material: seja a exploração capitalista que resulta na colonização, ocupação e homogeneização do novo mundo por meio de uma proletarização forçada de todos que encontra, seja por meio do processo de esgotamento da natureza, que seria condição material desses mundos possíveis. Em ambos os casos, podemos encarar esse esforço de pensar como uma tentativa de testemunhar os mundos possíveis que existem no interior do nosso próprio mundo e que não são elementos exteriores a ele.

Mas não é apenas em casos de multiplicação de pontos de vista que encontramos o problema da exploração intensiva dos mundos possíveis. Mesmo em trabalhos que aparentemente não têm relação com essa situação de esgotamento que descrevemos acima, vemos o mesmo tipo de movimento investigativo que nos permitiria perguntar se, por trás deles, não há motivações semelhantes. O trabalho de Markus Gabriel, por exemplo, procura realizar esse tipo de investigação sem entrar nas discussões etnológicas ou etológicas que Viveiros de Castro e Shaviro realizam ou sem fazer referência à crise generalizada

$16 \quad$ Esta que seria a perspectiva humana, a única que existe, considerando a maneira como nos mitos ameríndios costuma-se tomar os animais como tendo sido em algum momento humanos, de modo que, mesmo que tenham se transformado em determinados animais, nunca deixam de ser completamente humanos. 
por que passamos. Na obra de Gabriel, podemos tomar como reflexão sobre o tema dos mundos possíveis a sua desconstrução da noção de mundo, isto é, a negação de uma possibilidade do mundo como totalidade em favor de uma pluralização daquilo que ele chamará de campos de sentido (Gabriel, 2015).

Essa nossa investigação é apenas o movimento inicial de uma pesquisa que poderia avaliar, em cada caso, em que medida cada um desses filósofos contemporâneos faz esse movimento de pluralização interna dos mundos possíveis. Considerando, porém, as limitações de espaço e de tempo envolvidas na confecção desse trabalho, não temos condições de - e nem sequer aspiramos a - produzir uma síntese geral. Esperamos ter justificado por que o problema dos mundos possíveis perpassa esse grande número de autores e pode servir como um vetor para identificar esse movimento filosófico de maneira não arbitrária.

Diante do esgotamento da nossa imaginação e da nossa capacidade de agir, esses filósofos procuram mundos possíveis imanentes à nossa realidade. É isso que estamos chamamos de retomada dessa questão clássica da história da filosofia. Trata-se, portanto, de uma exploração intensiva dos mundos possíveis que permite pensar saídas para nossos impasses políticos, ecológicos e metafísicos atuais.

\section{Referências:}

ARANTES, Paulo. O novo tempo do mundo. São Paulo: Boitempo, 2014.

AZEVEDO, Raquel de. A pirâmide dos infinitos mundos possíveis de Leibniz. 2019. 166f. Tese (doutorado) - Pontifícia Universidade Católica do Rio de Janeiro, Departamento de Filosofia, 2019.

BRYANT, Levi (org.); SRNICEK (org.), Nick; HARMAN, Graham (org.). The speculative turn: continental materialism and realism. Melbourne: re.press, 2011.

COOLE, Diana (org.); FROST, Samantha (org.). New materialisms: ontology, agency, and politics. Durham: Duke University Press, 2010. 
DANOWSKI, Déborah; VIVEIROS DE CASTRO, Eduardo. Há mundo por vir?: ensaio sobre os medos e os fins. Florianópolis: Cultura e Barbárie, 2014.

DELEUZE, Gilles; GUATTARI, Félix. O que é a filosofia?. Trad. Bento Prado Jr. e Alberto Alonso Muñoz. São Paulo: Editora 34, 1997.

DESPRET, Vinciane. Uma carta ao artista. Trad. Juliana Fausto. [S.1.: s.n.], 2014. Disponível em: <https://nosanimais.files.wordpress. com/2014/11/carta-ao-artista-vinciane-despret.pdf > . Acesso em: 15 jun. 2019.

FERRARIS, Maurizio. Introduction to new realism. Trad. Sarah De Sanctis. London: Bloomsbury, 2015.

FISHER, Mark. Capitalist realism. Winchester: O books, 2009.

GABRIEL Markus. Fields of sense: a new realist ontology. Edinburgh: Edinburgh University Press, 2015.

GARCIA, Tristan. "Une boussole conceptuelle" in: ALLOA, Emmanuel (org.); DURING, Élie (org.). Choses em soi: métaphysique du réalisme. Paris: PUF, 2018.

KOSELLECK, Reinhart. Crítica e crise: uma contribuição à patogênese do mundo burguês. Trad. Luciana Villas-Boas Castelo-Branco. Rio de Janeiro: Contraponto, 1999.

KOSELLECK, Reinhart. Futuro passado: contribuição à semântica dos tempos históricos. Trad. Wilma Patrícia Maas e Carlos Almeida Pereira. Rio de Janeiro: Contraponto, 2006

LATOUR, Bruno. Enquête sur les modes d'existence : Une anthropologie des Modernes. Paris: La Découverte, 2012.

LATOUR, Bruno. Facing gaia. Trad. Catherine Porter. Cambridge: Polity Press, 2017.

MARX, Karl. O capital: crítica da economia política: livro I: o processo de produção do capital. Trad. Rubens Enderle. São Paulo: Boitempo, 2013

MARX, Karl; ENGELS, Friedrich. Manifesto comunista. Trad. Álvaro Pina e Ivana Jinkings. São Paulo: Boitempo, 2010.

MEILLASSOUX, Quentin. Après la finitude. Paris: Éditions du Seuil, 2012.

MEILLASSOUX, Quentin. Science fiction and extro-fiction. Trad. Alyosha Edlebi. Minneapolis: Univocal, 2015.

MONTEBELLO, Pierre. Métaphysiques cosmomorphes: la fin du monde humain. Dijon: Les presses du réel, 2015.

NIEMOCZYNSKI, Leon. Speculative realism: an epitome. Leeds: Kismet Press, 2017 
SHAVIRO, Steven. Discognition. London: Repeater Books, 2016. Livro eletrônico.

STENGERS, Isabelle. Cosmopolitics I. Trad. Roberto Bonono. Minneapolis: University of Minnesota Press, 2010.

STENGERS, Isabelle. No tempo das catástrofes. Trad. Eloisa Araújo Ribeiro. São Paulo: Cosac Naify, 2015.

STREECK, Wolfgang. How will capitalism end?. New York: Verso, 2016.

VIVEIROS DE CASTRO, Eduardo. Metafísicas Canibais. São Paulo: Cosac Naify, 2015.

WALLERSTEIN, Immanuel. Capitalismo histórico e civilização capitalista. Trad. Renato Aguiar. Rio de Janeiro: Contraponto, 2001. 
